\title{
To anchor or not to anchor self-expanding metal stents in malignant esophageal disease: Is this still a question?
}

\section{다)(1) $\odot$}

Authors

Juan P. Gutierrez¹, Steffen Rickes², Klaus Mönkemüller ${ }^{3}$

Institutions

1 Clinica del Aparato Digestivo, Hospital Italiano, Montevideo, Uruguay

2 Department of Gastroenterology, Helios Klinikum, Oschersleben, Germany

3 Department of Gastroenterology, Helios Klinikum, Kronach, Germany

\author{
Bibliography \\ DOI https://doi.org/10.1055/s-0043-118658 | \\ Endoscopy International Open 2017; 05: E1050-E1051 \\ (c) Georg Thieme Verlag KG Stuttgart · New York \\ ISSN 2364-3722
}

Corresponding author

Klaus Mönkemüller, MD, PhD, FASGE, Division

of Gastroenterology, Helios Frankenwaldklinik,

Friesenerstr. 44, Kronach, Germany

moenkemueller@yahoo.com
Fully or partially covered self-expandable metal stents (SEMSs) are one of the main pillars for the palliative therapy of esophageal cancer [1]. Furthermore, SEMSs are also useful to treat a myriad of esophageal conditions, including benign stenosis, anastomotic insufficiency after gastroesophageal operations, and various types of leaks, perforations, and fistulae [2-4]. When Symonds inserted the first stent for the palliation of esophageal cancer, it was a rudimentary tube made of rubber originating from the tropical tree gutta percha [5]. Although these rubber stents improved the patient's ability to ingest some nutrients, mainly liquids and semi-liquids, they soon became dislodged and migrated distally. Thus, the advent of the fully or partially covered SEMS was a major breakthrough in the therapy and palliation of esophageal diseases $[1,6,7]$. Nonetheless, despite improvements in design, with proximal or mid-stent tulips, various shapes and diameters, and the presence of outward, expansive radial forces, these SEMSs still have high migration rates [2,6-9]. Therefore, experts all over the world have proposed additional methods to prevent stent migration, including strings, through- and over-the-scope clips (OTSCs), and suturing devices [3, 4, 6, 10-12].

A common misconception is that in the presence of stenotic esophageal disease due to intrinsic or extrinsic neoplasms, SEMS migration occurs only rarely. However, this is not the case, especially in patients with malignant dysphagia and strictures that allow passage of the endoscope, and in those who have undergone chemo- and/or radiation therapy $[6,7]$. For this reason, the study by Watanabe et al., presented in this issue of Endoscopy International Open, is interesting [13].

The investigators from Fukushima, Japan, present the first study evaluating the feasibility of esophageal SEMS fixation with an OTSC for patients with malignant esophageal stricture. The investigators set out not only to determine the technical success of this technique, but also to investigate the clinical success, which was defined as an improvement of at least 1 grade in the dysphagia score 1 week after stent placement. A total of 12 patients with malignant esophageal strictures and a dysphagia score of at least 2 who were not candidates for curative surgery were included. The technical success rate was 100 $\%$ and successful application of the OTSC was accomplished in all SEMS placements, with a median procedure time required for OTSC placement of 11 minutes, and no adverse events. The clinical success rate was $92.3 \%$, with only one patient not showing improvement in dysphagia. The median follow-up period after SEMS placement was 2 months and no delayed adverse events, including migration of the SEMS, were observed during this follow-up period.

In summary, this study showed that SEMS placement and fixation with an OTSC for malignant esophageal strictures was successfully, safely, rapidly, and easily accomplished in all cases, and resulted in dysphagia resolution in the majority of patients.

Does this mean that all patients with malignant dysphagia require stent fixation after stent placement? The answer is definitely not. However, the practicing endoscopist should be aware that stent fixation should be considered in a significant percentage of patients with malignant dysphagia (i.e. those in whom the scope can still pass through the stenosis, patients receiving or who have received chemo- and/or radiation therapy), and in most patients with benign disease [6,10-12].

Is the additional cost associated with stent fixation worth it? We believe that the costs are justified because stent migration 
and the subsequent need for extraction result in additional costs, and are also risky and annoying for patients.

What fixation technique should be used? Traditional or standard through-the-scope clips do not hold stents efficiently. Additionally, utilizing more than two of these clips is more expensive than one OTSC. On the other hand, suturing devices, such as the Endo Stitch, have shown promising results and should be considered as alternatives in centers with expertise with this device. Nonetheless, the endostitching device is at least 5-6-times more expensive than one OTSC. This leads us to the final point, which is evidence in practice. Until now, all studies reporting on fixation of SEMSs are case series and feasibility studies, and none of them have considered costs. We now need prospective, comparative studies evaluating effectiveness and efficiency of various fixation methods for covered SEMSs, always remembering that any method used to anchor a fully covered stent should be easy to handle, removable, and cost-effective.

\section{Competing interests}

Dr. Mönkemüller is a consultant for Ovesco (Tübingen, Germany).

\section{References}

[1] Spaander MC, Baron TH, Siersema PD et al. Esophageal stenting for benign and malignant disease: European Society of Gastrointestinal Endoscopy (ESGE) Clinical Guideline. Endoscopy 2016; 48: 939-948

[2] van Boeckel PG, Sijbring A, Vleggaar FP et al. Systematic review: temporary stent placement for benign rupture or anastomotic leak of the oesophagus. Aliment Pharmacol Ther 2011; 33: 1292 - 1301
[3] Mudumbi S, Mönkemüller K. Endoscopic re-anastomosis of esophagus and stomach using dual endoscope technique with two fully covered metal stents and over-the-scope-clip. Dig Endosc 2014; 26: $493-494$

[4] Gutiérrez JP, Martínez-Alcalá A, Kröner T et al. Endoscopic removal of a mesh penetrating into the esophagus using overtube-assisted endoscopy, fully covered metal stent, and over-the-scope clip. Gastrointest Endosc 2016; 84: 523

[5] Symonds C]. The treatment of malignant stricture of the oesophagus by tubage or permanent catheterism. Br Med J 1887; 1: 870-873

[6] Yang J, Siddiqui AA, Kowalski TE et al. Esophageal stent fixation with endoscopic suturing device improves clinical outcomes and reduces complications in patients with locally advanced esophageal cancer prior to neoadjuvant therapy: a large multicenter experience. Surg Endosc 2017; 31: 1414-1419

[7] Kinsman KJ, DeGregorio BT, Katon RM et al. Prior radiation and chemotherapy increase the risk of life-threatening complications after insertion of metallic stents for esophagogastric malignancy. Gastrointest Endosc 1996; 43: 196-203

[8] Walter D, van den Berg MW, van Hooft JE et al. A new fully covered metal stent with anti-migration features for the treatment of malignant dysphagia. Endoscopy 2014; 46: $1101-1105$

[9] Schoppmann SF, Langer FB, Prager G et al. Outcome and complications of long-term self-expanding esophageal stenting. Dis Esophagus 2013; 26: $154-158$

[10] Martins BC, Retes FA, Medrado BF et al. Endoscopic management and prevention of migrated esophageal stents. World J Gastrointest Endosc 2014; 6: 49-54

[11] Vanbiervliet G, Filippi J, Karimdjee BS et al. The role of clips in preventing migration of fully covered metallic esophageal stents: a pilot comparative study. Surg Endosc 2012; 26: 53 - 59

[12] Mudumbi S, Velazquez-Aviña J, Neumann H et al. Anchoring of selfexpanding metal stents using the over-the-scope clip, and a technique for subsequent removal. Endoscopy 2014; 46: 1106 - 1109

[13] Watanabe K, Hikichi T, Nakamura J et al. Feasibility of esophageal stent fixation with an over-the-scope-clip for malignant esophageal strictures to prevent migration. Endosc Int Open 2017: 5 